\title{
RESENHA
}

\section{O que foi Selecionado da FAP (Psicoterapia Analítica Funcional) Durante Vinte Anos de Prática}

What was Selected from FAP (Functional Analytic Psychotherapy) During Twenty Years of Practice

\author{
Francielly Peron \\ Guilherme Previdi Olandoski \\ Maria Rita Drula do Nascimento \\ Patrícia Hobold Meurer \\ Rosana Angst \\ Sulliane Teixeira Freitas \\ Jocelaine Martins da Silveira \\ Universidade Federal do Paraná
}

Tsai, M., Kohlenberg, R. J., Kanter, J. W., Kohlenberg, B., Follette, W. C., \& Callaghan, G. M. (2009). A guide to Functional Analytic Psychotherapy: Awareness, courage, love, and behaviorism. New York: Springer.

Os autores escreveram o livro visando instrumentalizar terapeutas analítico-comportamentais e de outras orientações teóricas na aplicação da Psicoterapia Analítica Funcional (FAP), conscientes de seu impacto e disseminação pelo mundo, ao longo de aproximadamente duas décadas. Os capítulos, escritos em coautoria com quatorze colaboradores, introduzem a FAP, seus fundamentos conceituais e formas de manejo, destacando o papel do terapeuta. O livro instrui terapeutas para que desenvolvam em si mesmos, e em seus clientes, consciência, coragem e amor.

No capítulo um, são introduzidos conceitos fundamentais para a FAP, como: comportamento, função versus topografia e funções de estímulo presentes no contexto terapêutico. Os autores se abstêm, nesse ponto, de comentar as funções punidoras possíveis no contexto da sessão, descrevendo funções reforçadoras, discriminativas e eliciadoras próprias da interação terapeuta-cliente. $\mathrm{O}$ foco no aqui-agora é proposto como um requisito para a aplicação da FAP. O primado do reforço natural sobre o arbitrado é apresentado, assim como as instâncias de comportamentos clinicamente relevantes $(\mathrm{CRB})$.

O capítulo dois apresenta dados de pesquisa sobre a FAP, que é uma estratégia fundamentada em princípios comportamentais derivados teórica e empirica- mente de décadas de experimentação em laboratório, embora essa estratégia, em si mesma, ainda requeira avaliação empírica controlada. Os autores apoiaram-se em dados consolidados na literatura sobre a relação terapêutica, localizando no reforço natural, próprio da interação terapeuta-cliente, o potencial gerador dos assim chamados mecanismos de mudança clínica.

O capítulo três trata da avaliação e formulação de caso, esclarecendo que, ao interagir com o cliente, os comportamentos clinicamente relevantes começam a ser identificados, mediante o relato de eventos fora da sessão e observação direta do comportamento na sessão. Desta forma, a avaliação e formulação de caso ocorrem de maneira funcional e idiográfica. O Functional Idiographic Assessment Template (FIAT) é recomendado para apoiar a formulação do caso na FAP.

No quarto capítulo, os autores descrevem as cinco regras para a implementação da FAP. Vale destacar a primeira regra, que é considerada o coração da FAP e que recomenda a observação de CRBs. O terapeuta pode melhorar sua habilidade de observar CRBs com o uso de questionários, como o FIAT; com a identificação do significado nas verbalizações do cliente e/ou com a observação de suas próprias emoções, sendo, portanto, obrigado a haver-se com suas próprias deficiências e a promover mudanças em si mesmo, quando necessário. 
No quinto capítulo, o desenvolvimento do senso de self e suas implicações clínicas são discutidos. Para fortalecer o controle privado, o terapeuta pode reforçar a fala na ausência de dicas externas específicas; pode combinar tarefas terapêuticas, solicitando que o cliente diga tudo o que lhe ocorrer, sem julgar ou censurar e pode ainda reforçar tantas declarações "Eu X" quanto possível. Em seguida, os autores apresentam a noção de mindfulness, que trata da suspensão do julgamento de pensamentos e ações presentes. $\mathrm{O}$ não julgamento implica na ausência da esquiva ou de outras tentativas de controlar os eventos aversivos. Os autores sugerem que os exercícios de auto-observação, sensibilização, relaxamento e aceitação promovem o mindfulness.

No sexto capítulo, os autores tratam da noção de intimidade e de sua importância para a FAP. Recorrem ao conceito, segundo o qual, intimidade é o responder interpessoal vulnerável à punição. A intimidade requer revelações de pensamentos ou sentimentos, resultando em um sentimento de conexão e apego em relação ao outro. Entre as implicações terapêuticas da intimidade estão a possibilidade de evocar CRBs e a melhora no repertório interpessoal, permitindo que o cliente enfrente decepções inevitáveis de um relacionamento íntimo.

O capítulo sete descreve o curso da terapia, isto é, as fases do tratamento na FAP. Cada fase da terapia tem focos distintos e tende a evocar diferentes tipos de CRBs. Antes do início do tratamento, é esclarecido ao cliente que a FAP é um processo interpessoal intenso. No início da terapia, realiza-se a formulação do caso e a avaliação, devendo o terapeuta estabelecer-se como reforçador positivo, construindo as bases para a relação terapêutica. Os autores sugerem a utilização de tarefas e questionários para avaliar a relação terapêutica. Na fase intermediária da terapia, o CRB1 é enfocado pelo terapeuta, que realiza seu bloqueio ou leva o cliente a conscientizar-se dele, ao mesmo tempo em que promove o CRB2. O cliente é convidado a emitir CRB2 na sua vida fora da sessão. O CRB1 de evitação emocional precisa ser observado e o CRB2 de contato com a experiência deve ser encorajado. Nessa fase, idealmente, o CRB2 ocorre em todas as sessões. O final da terapia é uma oportunidade para ajudar o cliente a construir um novo repertório relacionado à perda e ao término de relacionamentos.

O capítulo oito trata da supervisão e do desenvolvimento pessoal do terapeuta. A supervisão para a prática da FAP visa o saber que e o saber como. $\mathrm{O}$ primeiro pode ser descrito como o saber intelectual em relação ao desenvolvimento de habilidades, as quais podem ser aprendidas via modelação, instruções específicas e feedback. O saber como pode ser definido como o que o terapeuta faz - corresponde à aprendizagem do comportamento modelado por contingência. O saber como pode ser aprendido na exposição direta a um relacionamento interpessoal intenso com o supervisor, no qual as respostas emocionais são tratadas. O capítulo apresenta modelos de supervisão de FAP em grupo e recomenda que o ambiente da supervisão seja especial no sentido de promover autoobservação e autoconhecimento.

No último capítulo, os autores propõem que o terapeuta esteja comprometido com os problemas globais, designando essa prática de Green FAP. Os valores do terapeuta devem ser incluídos na terapia, de algum modo, desde que estejam relacionados com a preocupação e a ajuda ao outro, com a consciência e a responsabilidade social e com a utilização de habilidades e talentos que contribuem para o mundo. Compete ao terapeuta apresentar seus valores desde o início para o cliente, que então pode decidir se leva o processo terapêutico adiante.

Para os iniciantes na prática da FAP, o livro é um guia entusiástico e didático. Para os terapeutas praticantes da FAP há anos, a leitura do livro inspira a preocupação em viabilizar medidas da relação terapêutica e promover avaliações mais controladas dessa estratégia. Instrumentos e técnicas são sugeridos, com destaque para as que facilitam o mindfulness. É possível que alguns procedimentos apresentados no livro produzam efeitos terapêuticos diferentes dependendo da cultura - por exemplo, a utilização de questionários para a avaliação da interação terapeuta/cliente e a formalização de contrato para o início de um atendimento, o qual explicita a intensidade da relação terapêutica.

Promover um self controlado por dicas privadas, exercitar o mindfulness e estar implicado pessoalmente no sucesso do tratamento foram notadamente respostas selecionadas no repertório do terapeuta ao longo das décadas de prática da FAP. Quanto à proposta da Green FAP, o tempo dirá se essa prática será selecionada nos terapeutas.

Embora, em alguns pontos do texto, a linguagem pareça coloquial e as ideias sobre terapia repitam os já consagrados fatores terapêuticos comuns, as palavras consciência, coragem e amor, resumem a prescrição de ações do terapeuta e de seus resultados no repertório do cliente. Conceitos básicos foram novamente apresentados e refinados quanto à observação do 
comportamento do terapeuta. Clientes e terapeutas são encorajados a aumentar sua observação de seus próprios comportamentos no aqui/agora da sessão e em situações fora dela. Essa consciência é fundamental para as intervenções clínicas. Nela, o terapeuta inspira suas interpretações do aqui-agora para o cliente e é por meio dela que o cliente adquire autoconhecimento. A coragem é necessária nas interações de intimidade - clientes e terapeutas arriscam-se o tempo todo no contexto terapêutico, com autorrevelações e tolerância de estimulação aversiva advinda de feedbacks e da intensidade de suas emoções. No que diz respeito ao amor, parece que, ao longo desses mais de vinte anos de aplicação da FAP, os supervisores puderam perceber que a mera compreensão intelectual de seu manejo não produz resultados tão bons quanto quando esta vem acompanhada de um repertório do terapeuta naturalmente reforçador do "bem" do outro (o amor agápico). Isto é, o repertório de amor agápico do terapeuta e do cliente é, do ponto de vista técnico, a garantia de reforço natural nas relações humanas e na relação terapêutica.
O livro sugere que todos esses anos da prática da FAP selecionaram as respostas do terapeuta focadas no aqui/agora de arriscar-se na relação terapêutica, de reforçar naturalmente o bem do cliente, de distanciar-se da literalidade da linguagem (mindfulness) e de gerar tactos de eventos privados que incrementam o senso de self.

\section{REFERÊNCIAS}

Tsai, M., Kohlenberg, R. J., Kanter, J. W., Kohlenberg, B., Follette, W. C., \& Callaghan, G. M. (2009). A guide to Functional Analytic Psychotherapy: Awareness, courage, love, and behaviorism. New York: Springer.

\section{Sobre os autores da resenha:}

Francielly Peron: Psicóloga, mestranda em Psicologia pela Universidade Federal do Paraná.

Guilherme Previdi Olandoski: Psicólogo, mestrando em Psicologia pela Universidade Federal do Paraná.

Maria Rita Drula do Nascimento: Psicóloga, aluna de disciplina isolada no Mestrado em Psicologia da Universidade Federal do Paraná.

Patrícia Hobold Meurer: Psicóloga, mestranda em Psicologia pela Universidade Federal do Paraná.

Rosana Angst: Psicóloga, aluna de disciplina isolada no Mestrado em Psicologia da Universidade Federal do Paraná.

Sulliane Teixeira Freitas: Psicóloga, mestranda em Psicologia pela Universidade Federal do Paraná.

Jocelaine Martins da Silveira: Psicóloga, doutora em Psicologia Clínica pela Universidade de São Paulo (2003). Professora adjunta do Departamento de Psicologia da Universidade Federal do Paraná. Docente do Mestrado em Psicologia da UFPR.

Endereço para correspondência: Universidade Federal do Paraná - Departamento de Psicologia - Praça Santos Andrade, 50 - sala 215 80060-000 Curitiba/PR. Endereço eletrônico: jocelainesilveira@ufpr.br. 